\title{
Research on Multiple-Split Load Sharing Characteristics of 2-Stage External Meshing Star Gear System in Consideration of Displacement Compatibility
}

\author{
Shuai Mo, ${ }^{1,2}$ Shuai Ma, ${ }^{2}$ Guoguang Jin, ${ }^{2}$ Yidu Zhang, ${ }^{3}$ Chao Lv, ${ }^{4}$ and Haruo Houjoh ${ }^{5}$ \\ ${ }^{1}$ The State Key Laboratory of Mechanical Transmissions, Chongqing University, Chongqing 400044, China \\ ${ }^{2}$ School of Mechanical Engineering, Tianjin Polytechnic University, Tianjin 300387, China \\ ${ }^{3}$ State Key Laboratory of Virtual Reality Technology and Systems, Beihang University, Beijing 100191, China \\ ${ }^{4}$ Tianjin Tanhas Group Co., Ltd., Tianjin 301600, China \\ ${ }^{5}$ Precision and Intelligence Laboratory, Tokyo Institute of Technology, Yokohama 226-8503, Japan
}

Correspondence should be addressed to Shuai Mo; moshuai2010@163.com

Received 7 July 2017; Revised 27 October 2017; Accepted 28 November 2017; Published 27 December 2017

Academic Editor: Anna Vila

Copyright (C) 2017 Shuai Mo et al. This is an open access article distributed under the Creative Commons Attribution License, which permits unrestricted use, distribution, and reproduction in any medium, provided the original work is properly cited.

\begin{abstract}
This paper studies the multiple-split load sharing mechanism of gears in two-stage external meshing planetary transmission system of aeroengine. According to the eccentric error, gear tooth thickness error, pitch error, installation error, and bearing manufacturing error, we performed the meshing error analysis of equivalent angles, respectively, and we also considered the floating meshing error caused by the variation of the meshing backlash, which is from the floating of all gears at the same time. Finally, we obtained the comprehensive angle meshing error of the two-stage meshing line, established a refined mathematical computational model of 2-stage external 3-split loading sharing coefficient in consideration of displacement compatibility, got the regular curves of the load sharing coefficient and load sharing characteristic curve of full floating multiple-split and multiple-stage system, and took the variation law of the floating track and the floating quantity of the center wheel. These provide a scientific theory to determine the load sharing coefficient, reasonable load distribution, and control tolerances in aviation design and manufacturing.
\end{abstract}

\section{Preface}

Two-stage external meshing planetary transmission system is widely used in aviation and special precision transmission field. The T53-L-11 turbo-axis aircraft engine produced by Lycoming (US Company) used two-stage external meshing planetary transmission system as its reducer. Located in the engine head and installed in the intake box, reducer transports the motivation from free turbine shaft to the second sun gear after decreasing speed and increasing torque. Two-stage star gear transmission has multiple duplicate gears with fixedaxes to share the load, its star gears do not revolve, and its characteristics are power split, high transmission power, and only one-side load bearing, and so on. Two-stage star gear transmission uses two-stage star gears, without the ring gear, directly output by two external gears, so that it overcomes the alternating load of planet gear in traditional planetary gear transmission, the difficulty in processing of ring gear, the centrifugal force caused by the rotation of carrier, and intermittent lubrication of planet gear. The system strength, stiffness, and working life and reliability of transmission system have greatly improved by using two-stage fixed-axis external meshing gears. In this paper, a precise load sharing characteristic analysis model is established for all gears with angular displacement compatibility, including bearing manufacturing errors, gear manufacturing errors (eccentricity error, tooth thickness error, and pitch error), installation error, and the meshing error caused by the variation of the meshing backlash resulting from simultaneous floating of all the gears. Research results can be used for aircraft engine and other precision special transmission systems in load sharing coefficients determination, vibration noise reduction, structure optimization, and error precision control. This paper provides scientific theory for the gear machining and assembly 


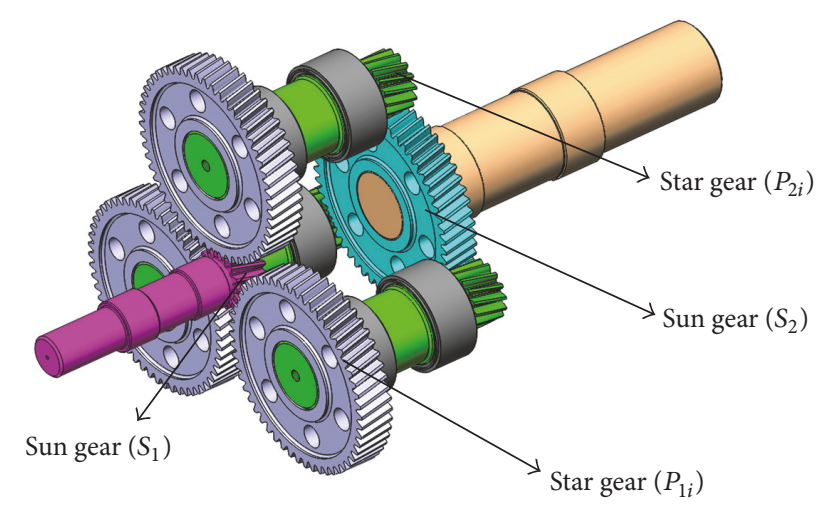

FIGURE 1: Two-stage external meshing planetary reducer movement diagram.

process and reveals load sharing mechanism for the multiplesplit system.

The load sharing has great influence on vibration and noise of power split transmission systems; therefore, domestic and foreign scholars continue to explore and research the load sharing of power split systems. Kahraman et al. studied statics load sharing characteristic of the planetary transmission systems [1-4]; Singh established analysis model of the load sharing characteristic of the planetary transmission systems [5, 6]; Wink and Sepra studied the method of tooth surface load distribution [7]; Bao et al. studied the static load sharing characteristics of star gear and closed differential transmission systems [8, 9]; Du et al. studied the load sharing characteristics of the planetary transmission systems and dual power splitting systems [10, 11]; and Mo et al. researched the natural characteristics of double-helical star gearing system for GTF aeroengine and load sharing behavior of wind turbine gearbox [12-15]; Mantriota deals with the performance of power split transmissions in wind energy systems to identify the power split configurations that require the minimum rated power of the regulator system, to reduce costs and the power losses [16]. Zhu et al. established a dynamic analysis model for 2-stage star gear train, where in the transmission error and the time-varying stiffness and backlash the nonlinear differential equations with multiple backlashes were considered and solved [17]. $\mathrm{Gu}$ et al. proposed a new type of spiral bevel gears power split system with cross axes transmission and its structure and working state were explained based on different forms of gear power split transmission including parallel axes, star gear train, and planetary gear train [18]. Shigley and Mischke have done much research work on mechanical design [19].

\section{Two-Stage External Meshing Star Gear Transmission System}

A movement diagram of two-stage external meshing star gearing transmission system used in a certain type of aircraft engine was shown in Figure 1. In each stage, 3 star gears and 2 external meshing were used, sun gear $S_{1}$ in the first stage is
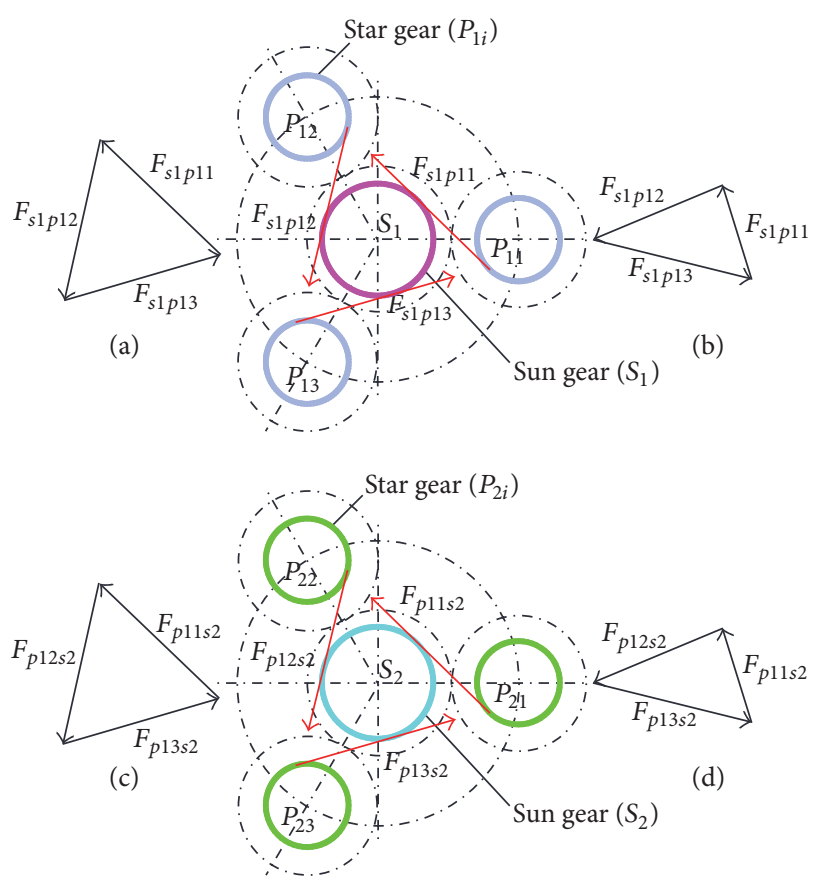

FIGURE 2: Load distribution between star gears.

TABLE 1: Star reducer gear parameters.

\begin{tabular}{lcccc}
\hline Name & Teeth number & Modulus & Input power & Input speed \\
\hline$Z_{s 1}$ & 15 & $1.5 \mathrm{~mm}$ & & \\
$Z_{p 1 i}$ & 54 & $1.5 \mathrm{~mm}$ & $100 \mathrm{~kW}$ & $40000 \mathrm{r} / \mathrm{min}$ \\
$Z_{p 2 i}$ & 15 & $1.5 \mathrm{~mm}$ & & \\
$Z_{s 2}$ & 54 & $1.5 \mathrm{~mm}$ & & \\
\hline
\end{tabular}

input side, and sun gear $S_{2}$ in the second stage is output side. Related parameters are shown in Table 1.

\section{Load Sharing Mechanism of Two-Stage Star Gearing Transmission System}

In planetary gear transmission, the center gear is usually used as a floating component. When the star gears are loaded unevenly, the floating component is forced to move until the load of several star gears tends to be evenly distributed. The load distribution diagrams of the sun gear in first stage and second stage are shown in Figure 2. In ideal stiffness and manufacturing accuracy, sun gear $S_{1}$ of first stage will float and the principal vector of $F_{s 1 p 1 i}$ is 0 : namely, $F_{s 1 p 11}+\cdots+$ $F_{s 1 p 13}=0$. And the main torque of sun gear $S_{1}$ is equal to the input torque. Sun gear $S_{2}$ of second stage will float, the principal vector of $F_{s 2 p 2 i}$ is 0 , namely, $F_{p 21 s 2}+\cdots+F_{p 23 s 2}=0$, and the main torque of sun gear $s_{2}$ is equal to the output torque.

If the floating components are under uniform load, the three normal meshing forces constitute a closed equilateral triangle, so that the load of star gear tends to be uniform, to achieve the purpose of share loading, as shown in situations (a) and (c). If the amounts of floating component and 


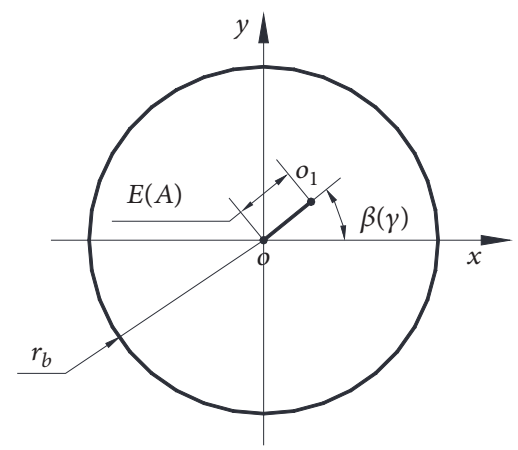

Figure 3: Diagram of manufacturing error and assemble error.

structure design are unreasonable and the manufacturing and installation error become large enough, then the three normal meshing forces constitute equilateral triangle, load distribution of star gear is uneven, and load sharing effect is bad, as shown in situations (b) and (d). The force in the actual product is approximately equilateral triangle, which bring in the load sharing coefficient of transmission system.

\section{Angular Meshing Error Analysis}

4.1. Equivalent Angular Meshing Error on Meshing Line. Taking the most common influence of star gear system on load sharing as an example, the equivalent error of meshing error is analyzed along meshing line. Other related errors (such as axial skew error, position error of star gear hole, and runout error) are also available by similar process. Finally, the comprehensive angle meshing error is obtained.

Manufacturing error and installation error of each component are shown in Figure 3, $o$ is the theoretical center position, $o_{1}$ is the actual center position, and the distance between two points is the error; $E$ is the manufacturing error, $A$ is the installation error, $\beta$ is the manufacturing error direction, $\gamma$ is the installation error direction, $\omega_{s 1}$ is the angular velocity of the sun gear $1, \omega_{p 1}$ is the angular velocity of the large star gear, $\omega_{p 2}$ is the angular velocity of the small star gear, $\omega_{s 2}$ is the angular velocity of the sun gear $2, \alpha_{w 1}$ is the meshing angle of the 1st external meshing, $\alpha_{w 2}$ is the meshing angle of the 2 st external meshing, $\phi_{i}$ is the position angle of the $i$ star gear relative to the first star gear, $\phi_{i}=2 \pi(i-1) / n$, $n$ is the number of star gears, $t$ is the time, and subscripts $s 1 / p 1 i / p 2 i / s 2$, respectively, represent the sun gear 1 , the firststage star gear $i$, the second-stage star gear $i$, and the sun gear 2. The equivalent error of meshing error is analyzed along the two-stage external meshing line. Supposing that the center of the star gear 1 is on the $x$-axis, as shown in Figure 4 , the direction of the equivalent meshing error out of the meshing line is defined as positive.

4.2. Comprehensive Angular Meshing Error. The accumulated meshing errors on the meshing lines of individual component can be obtained by superimposing meshing errors.

$$
\begin{aligned}
\varphi_{s 1 p 1 i}= & \varphi_{E s 1 i}+\varphi_{A s 1 i}+\varphi_{E b s 1 i}+\varphi_{E s 1 p 1 i}+\varphi_{A s 1 p i} \\
& +\varphi_{E b s 1 p 1 i}+\varphi_{b p s 1}+\varphi_{b p p 1 i}+\varphi_{t s 1}+\varphi_{t p 1 i}
\end{aligned}
$$

$$
\begin{aligned}
\varphi_{p 2 i s 2}= & \varphi_{E s 2 i}+\varphi_{A s 2 i}+\varphi_{E b s 2 i}+\varphi_{E p 2 i s 2}+\varphi_{A p 2 i s 2} \\
& +\varphi_{E b p 2 i s 2}+\varphi_{b p s 2}+\varphi_{b p p 2 i}+\varphi_{t s 2}+\varphi_{t p 2 i}
\end{aligned}
$$

The comprehensive meshing error between the $i$ th star gear and the 1st-stage sun gear is $\Delta \varphi_{s 1 p 1 i}^{0}\left(T_{s 1 p 1 i}\right)$, and the meshing error between the 2 nd-stage sun gear and the $i$ th star gear is $\Delta \varphi_{p 2 i s 2}^{0}\left(T_{p i s 2}\right)$.

$$
\begin{aligned}
& \Delta \varphi_{s 1 p 1 i}^{0}\left(T_{s 1 p 2 i}\right)=\varphi_{s 1 i}+\varphi_{s 1 p 1 i}+\varphi_{p 1 i} \\
& \Delta \varphi_{p 2 i s 2}^{0}\left(T_{p 2 i s 2}\right)=\varphi_{s 2 i}+\varphi_{p 2 i s 2}+\varphi_{p 2 i} .
\end{aligned}
$$

\section{Load Sharing Calculation Model of Two- Stage Star Gear Transmission System}

Figure 4 shows the load sharing calculation model of star gear transmission, which is made up of two parts. One is the model between the sun gear in the first stage and star gears, as shown in the first stage; the other is the model between the sun gear in the second stage and star gears, as shown in the second stage.

All gears are considered as floating components. Meshing pair, rotation pair, and elastic deformation of the support are expressed in equivalent stiffness. $K_{s 1 p} / K_{p s 2}$ represent the meshing stiffness of the sun gear 1 and the star gear, the meshing stiffness of star gear, and sun gear 2. $K_{s 1} / K_{s 2} / K_{p 1} / K_{p 2}$ represent the support stiffness of the sun gear 1 , the sun gear 2 , the first-stage small star gear, and the second-stage large star gear, respectively. The input torque is $T_{s 1}$. In the meshing pair $s 1 p 1 i$, the torque from big star gear to sun gear 1 is $T_{s 1 p 1 i}$. In the meshing pair $p 2 i s 2$, the torque from small star gear to sun gear 2 is $T_{s 2 p 2 i}$ and $T_{i j}$ represents the acting torque from $j$ gear to $i$ gear.

The drive torque is positive and the load torque is negative. $X_{s 1} / y_{s 1}$ are the floating amount in $x$ and $y$ directions of the first-stage star gear and $x_{s 2} / y_{s 2}$ are the floating amount in $x$ and $y$ directions of the second-stage star gear. $X_{s 2} / y_{s 2}$ are the floating amount in $x$ and $y$ directions of the second stage of sun gear. $\Omega_{p 1 i} / \Omega_{p 2 i}$ are the coefficient of load sharing for the two-stage star gear; $\Omega_{p}$ is the coefficient of load sharing for transmission system.

Torque equilibrium conditions of transmission system are as follows:

$$
\begin{aligned}
& T_{s 1}+\sum_{i}^{n} T_{s 1 p 1 i}=0 \\
& T_{p 1 i s 1}+T_{p 2 i s 2}=0 .
\end{aligned}
$$

$$
i=(1, \ldots, n)
$$

Relationship between acting torque and reaction torque is as follows:

$$
T_{p 1 i s 1}=-\left(\frac{r_{b p 1 i}}{r_{b s}}\right) T_{s 1 p 1 i}=0
$$



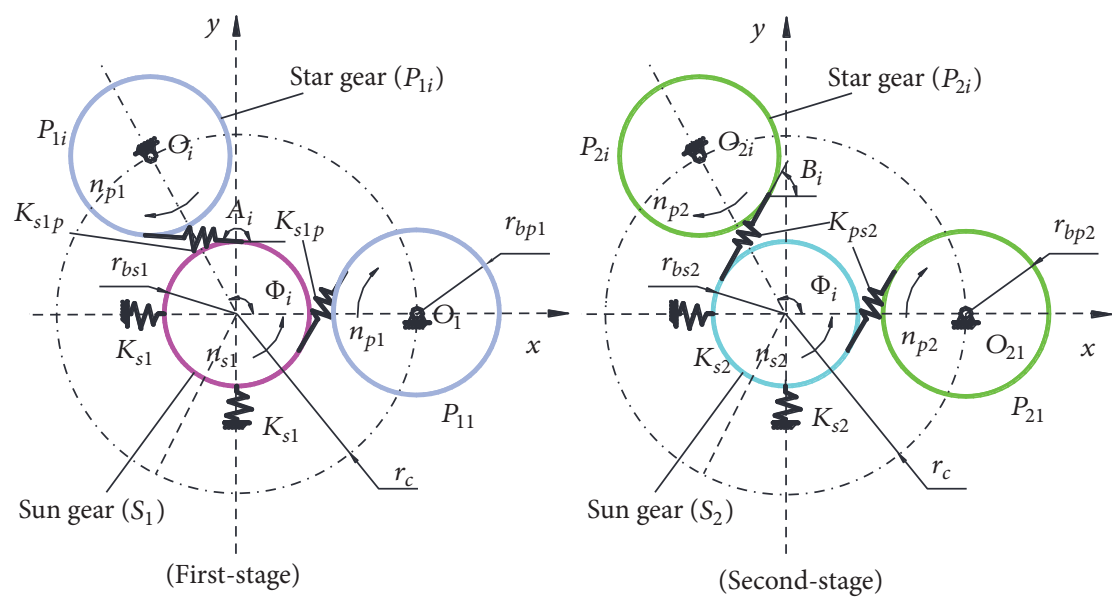

Figure 4: Calculation model of load sharing coefficient.

Using formulas (3) and (4), formula (5) can be obtained.

$$
\begin{aligned}
T_{s 1}+\sum_{i}^{n} T_{s 1 p 1 i} & =0 \quad(i=1, \ldots, n) \\
-\left(\frac{r_{b p 1 i}}{r_{b s 1}}\right) T_{s 1 p 1 i}+T_{p 2 i s 2} & =0 .
\end{aligned}
$$

The meshing angle of each gear pair satisfies the following relationship:

$$
\begin{aligned}
& \Delta \varphi_{s 1 p 1 i}\left(T_{s 1 p 1 i}\right)=\Delta \varphi_{s 1}-\left(\frac{r_{b p 1 i}}{r_{b s 1}}\right) \Delta \varphi_{p 1 i} \\
& \Delta \varphi_{p 2 i s 2}\left(T_{p 2 i s 2}\right)=\Delta \varphi_{p 2 i}-\left(\frac{r_{b s 2}}{r_{b p 2 i}}\right) \Delta \varphi_{s 2} .
\end{aligned}
$$

$\varphi_{i}$ represents the rotation angle of the gear $i, \Delta \varphi_{i j}\left(T_{i j}\right)$ represents an angle microdisplacement of the gear $i$ with respect to the gear $j$, namely, the load transmission error. $\Delta \varphi_{i j}\left(T_{i j}\right)$ is a function of $T_{i j}$. The transmission errors of the $i$ th meshing pair are converted into the equivalent angular meshing errors with respect to the sun gear 1 :

$$
\begin{aligned}
\Delta \varphi_{i} & =\Delta \varphi_{s 1 p 1 i}+\left(\frac{r_{b p 2 i}}{r_{b s 1}}\right) \Delta \varphi_{p 2 i s 2} \\
& =\Delta \varphi_{s 1}-\left(\frac{r_{b s 2}}{r_{b p 2 i}}\right) \Delta \varphi_{s 2} .
\end{aligned}
$$

The power transmission error of each split is equal to the equivalent angular meshing errors of the sun gear 1: namely, $\Delta \varphi_{1}=\cdots=\Delta \varphi_{3}$; the angular displacement coordination condition is as follows:

$$
\begin{aligned}
& \Delta \varphi_{s 1 p 11}\left(T_{s 1 p 11}\right)+\left(\frac{r_{b p 2 i}}{r_{b s 1}}\right) \Delta \varphi_{p 21 s 1}\left(T_{p 2 i s 2}\right) \\
& =\Delta \varphi_{s 1 p 1 i}\left(T_{s 1 p 1 i}\right)+\left(\frac{r_{b p 2 i}}{r_{b s 1}}\right) \Delta \varphi_{p 21 s 2}\left(T_{p 2 i s 2}\right) .
\end{aligned}
$$

Gear transmission error consists of the following two parts:

$$
\Delta \varphi_{i j}\left(T_{i j}\right)=\Delta \varphi_{i j}^{1}\left(T_{i j}\right)+\Delta \varphi_{i j}^{0}\left(T_{i j}\right)
$$

$\Delta \varphi_{i j}^{0}\left(T_{i j}\right)$ is the relative rotation angle of the initial interdentally space before the gear $j$ and the gear $i$ contacted (see in (5)); $\Delta \varphi_{i j}^{1}\left(T_{i j}\right)$ is the relative rotation angle of gear $j$ and gear $i$ after the deformation of the relative meshing point.

$$
\begin{aligned}
\Delta \varphi_{i j}^{1}\left(T_{i j}\right) & =\frac{F_{i j}}{\left(K_{i j} r_{i}\right)}=\frac{T_{i j}}{\left(K_{i j} r_{i}^{2}\right)} \\
\Delta \varphi_{s 1 p 1 i}^{1}\left(T_{s 1 p 1 i}\right) & =\frac{T_{s 1 p 1 i}}{\left(K_{s 1 p} r_{b s 1}^{2}\right)} \\
\Delta \varphi_{p 2 i s 2}^{1}\left(T_{p 2 i s 2}\right) & =\frac{T_{p 2 i s 2}}{\left(K_{p s 2} r_{b p 2 i}^{2}\right)} .
\end{aligned}
$$

Using formulas (2), (8), and (11), meshing transmission error can be obtained.

$$
\begin{aligned}
& \Delta \varphi_{s 1 p 1 i}\left(T_{s 1 p 1 i}\right)=\frac{T_{s 1 p 1 i}}{\left(K_{s 1 p} r_{b s 1}^{2}\right)}+\varphi_{s 1 p 1 i}+\varphi_{s 1 i} \\
& \Delta \varphi_{p 2 i s 2}\left(T_{p 2 i s 2}\right)=\frac{T_{p 2 i s 2}}{\left(K_{p s 2} r_{b s 2}^{2}\right)}+\varphi_{p 2 i s 2}+\varphi_{s 2 i} .
\end{aligned}
$$

The equilibrium equation of transmission system involving the gear floating is as follows:

$$
\begin{aligned}
\sum_{i=1}^{n} \frac{T_{s 1 p 1 i}}{r_{b s 1}} \cos A_{i}+K_{s 1} x_{s 1} & =0 \\
\sum_{i=1}^{n} \frac{T_{s 1 p 1 i}}{r_{b s 1}} \sin A_{i}+K_{s 1} y_{s 1} & =0 \\
\frac{T_{s 1 p 1 i}}{r_{b s 1}} \cos A_{i}-K_{p 1} x_{p 1 i} & =0
\end{aligned}
$$




$$
\begin{gathered}
\frac{T_{s 1 p 1 i}}{r_{b s 1}} \sin A_{i}-K_{p 1} y_{p 1 i}=0 \\
\frac{T_{p 2 i s 2}}{r_{b s 2}} \cos B_{i}+K_{p 2} x_{p 2 i}=0 \\
\frac{T_{p 2 i s 2}}{r_{b s 2}} \sin B_{i}+K_{p 2} y_{p 2 i}=0 \\
\sum_{i=1}^{n} \frac{T_{p 2 i s 2}}{r_{b s 2}} \cos B_{i}+K_{s 2} x_{s 2}=0 \\
\sum_{i=1}^{n} \frac{T_{p 2 i s 2}}{r_{b s 2}} \sin B_{i}+K_{s 2} y_{s 2}=0 \\
\Omega_{p 1 i}=\frac{\left|T_{s 1 p 1 i}\right|}{\left(T_{s 1} / n\right)} \quad(i=1,2, \ldots, n) \\
\Omega_{p 2 i}=\frac{\left|T_{p 2 i s 2}\right|}{\left(r_{b p 1 i} / r_{b p 2 i}\right)\left(T_{s 1} / n\right)} .
\end{gathered}
$$

Using formulas (6), (9), (13), and (14), the average load sharing coefficient of star gear can be obtained:

$$
\Omega_{p}=\max \left(\Omega_{p 1 i}, \Omega_{p 2 i}\right) .
$$

The more star gears, the bigger load sharing coefficient and the smaller dimension for radius of gearing system. If the load sharing coefficient of gearing system is much larger than 1 , it means load sharing condition is not well, which makes the gear have enough strength margin which will cause the gearing system to became heavy. The aeroengine has a strict study of weight; load sharing coefficient equal to 1 is the ideal condition; this means meshing force of gearing system is equal in each star gear. At the same time, it also means not have unnecessary weight of gearing system.

\section{Load Sharing Characteristics of Two-Stage Star Gear Transmission System}

From the ideal center line position and shape tolerance standard (GB1182-1184-80), gear manufacturing and installation errors can be obtained, the location errors were taken as $6 \mu \mathrm{m}$, and the phase was taken as $0.25^{\circ}$. Tooth thickness, pitch section, and bearing error are also taken as $6 \mu \mathrm{m}, K_{s 1 p}=$ $K_{p s 2}=1 \times 10^{7} \mathrm{~N} / \mathrm{m}, K_{s 1}=4 \times 10^{7} \mathrm{~N} / \mathrm{m}, K_{s 2}=8 \times 10^{7} \mathrm{~N} / \mathrm{m}$, $K_{p 1}=4 \times 10^{7} \mathrm{~N} / \mathrm{m}$, and $K_{p 2}=8 \times 10^{7} \mathrm{~N} / \mathrm{m}$.

In the condition of all manufacturing and installation errors at the same time, the load sharing characteristics of system were shown in Figure 5, and the load sharing coefficients of star gear were 1.0179, 1.0136, and 1.0619. The load sharing coefficient of system was 1.0619. The load sharing coefficient of gearbox for wind turbine at certain type is 1.088 [13], and the load sharing coefficient of gearing system for aeroengine is less than that of wind turbine, which also

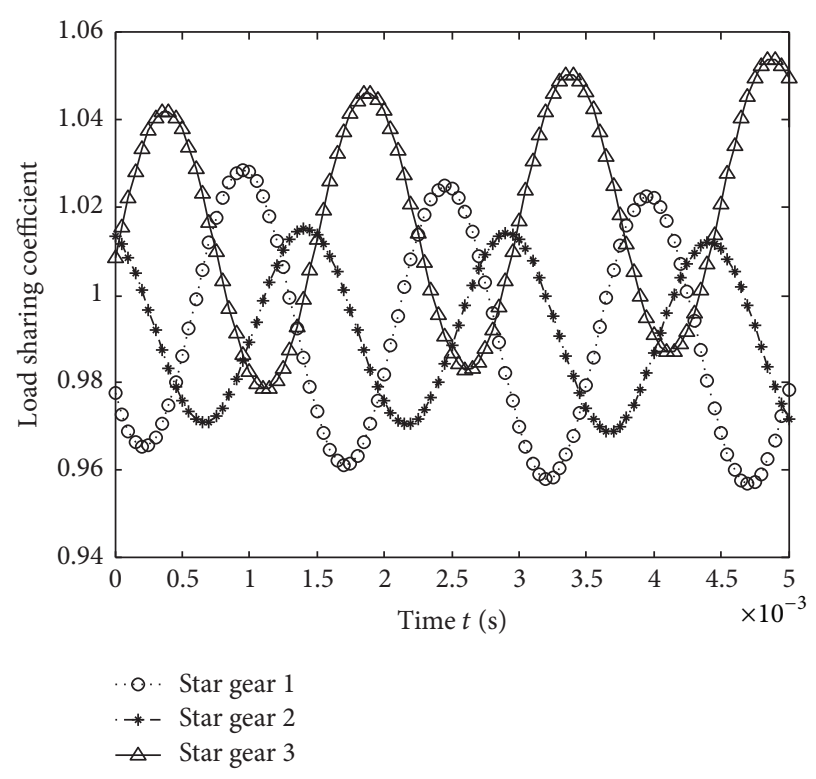

FIGURE 5: Load sharing curve of the first-stage star gear.

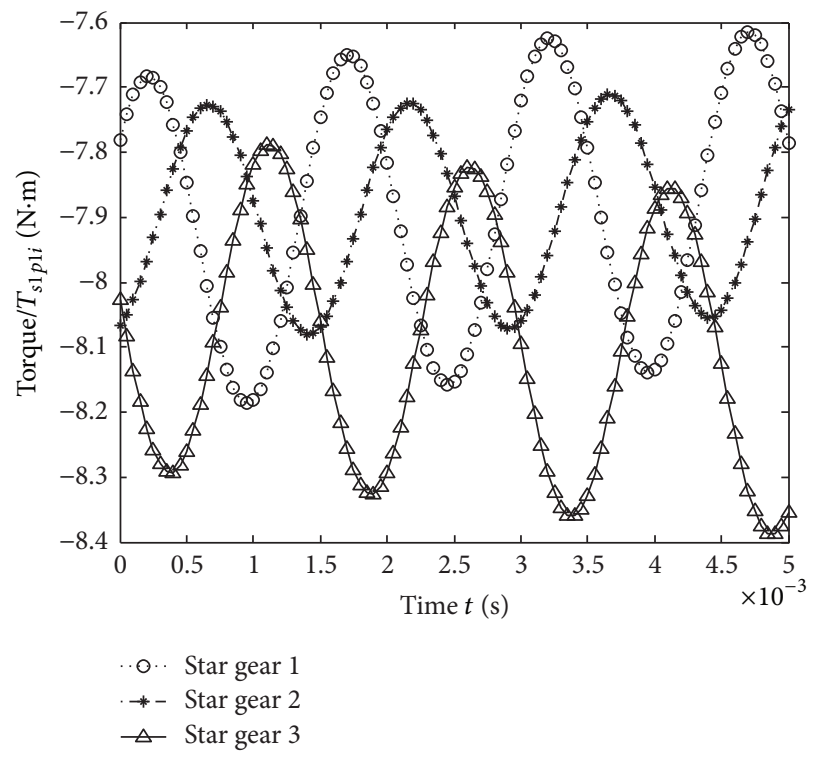

Figure 6: Acting torque from big star gear of the first stage to sun gear 1.

proves that the result is right because the level of precision for aeroengine is higher than wind turbine. Change rules of $T_{s 1 p 1 i}, T_{p 2 i s 2}$ are shown in Figures 6 and 7. Figures 8-11 show the floating orbit and floating amounts of the center gear.

Figure 5 is the load sharing curve for three star gears of first stage; load sharing coefficient of the first star gear is 1.0179, load sharing coefficient of the second star gear is 1.0136, and load sharing coefficient of the third star gear is 1.0619. The load sharing coefficients of three star gears are not the same which means the acting force of the three star gears is not the same. The load sharing coefficient is 1 in ideal condition, which means the acting force in each star gear is equal. In fact, 


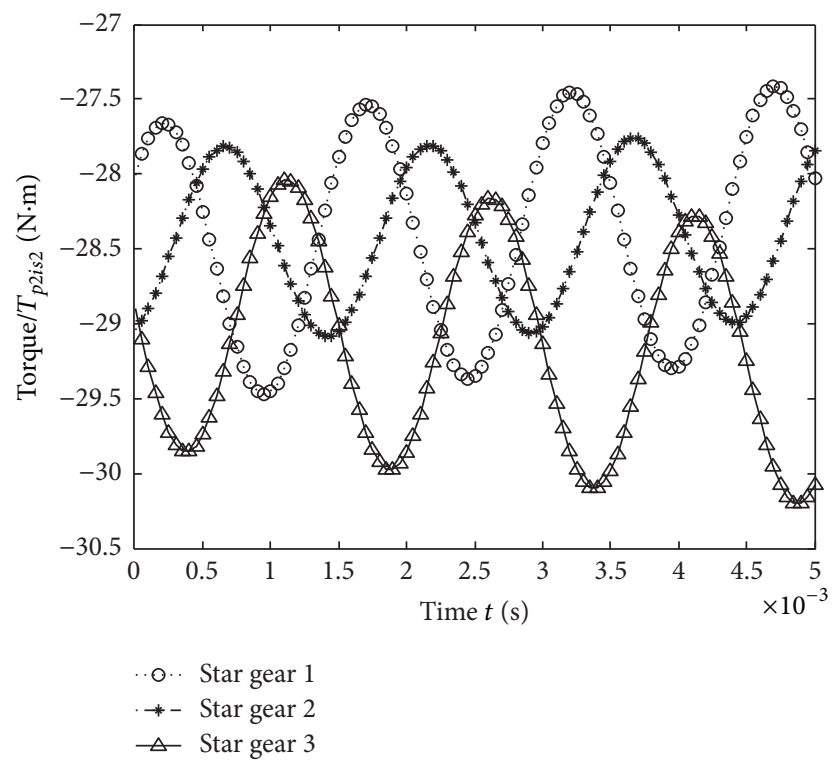

Figure 7: Acting torque from sun gear 2 to small star gear of the second stage.

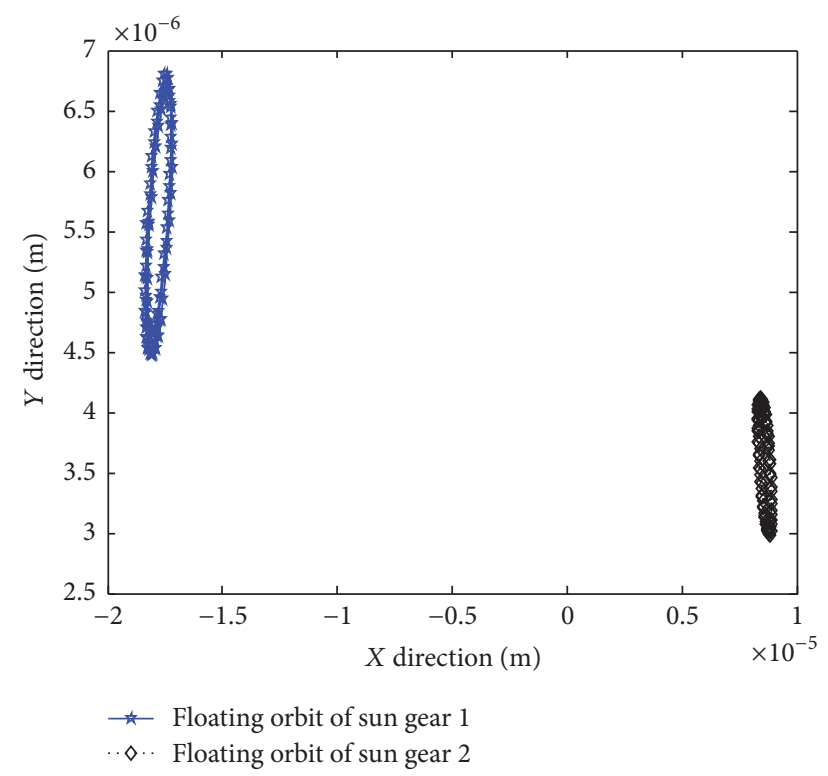

FIGURE 8: The floating orbit of first-stage sun gear $\left(S_{1}\right)$ and secondstage sun gear $\left(S_{2}\right)$.

acting force of the third star gear is the maximum value, and acting force of the second star gears is the minimum value.

Figure 6 is the acting torque curve from big star gear $(p 1 i)$ of first stage to sun gear $1(s 1)$, acting torque of the first star gear in first stage ( $p 11)$ is $8.2 \mathrm{Nm}$, acting torque of the second star gear in the first stage ( $p 12)$ is $8.1 \mathrm{Nm}$, and acting torque of the third star gear in the first stage $(p 13)$ is $8.4 \mathrm{Nm}$. The acting torque of three star gears is not the same which means the acting force of the three star gears in the first stage is not the same. The acting torque of three star gears is the same in ideal condition, which means the acting force in each star gear is

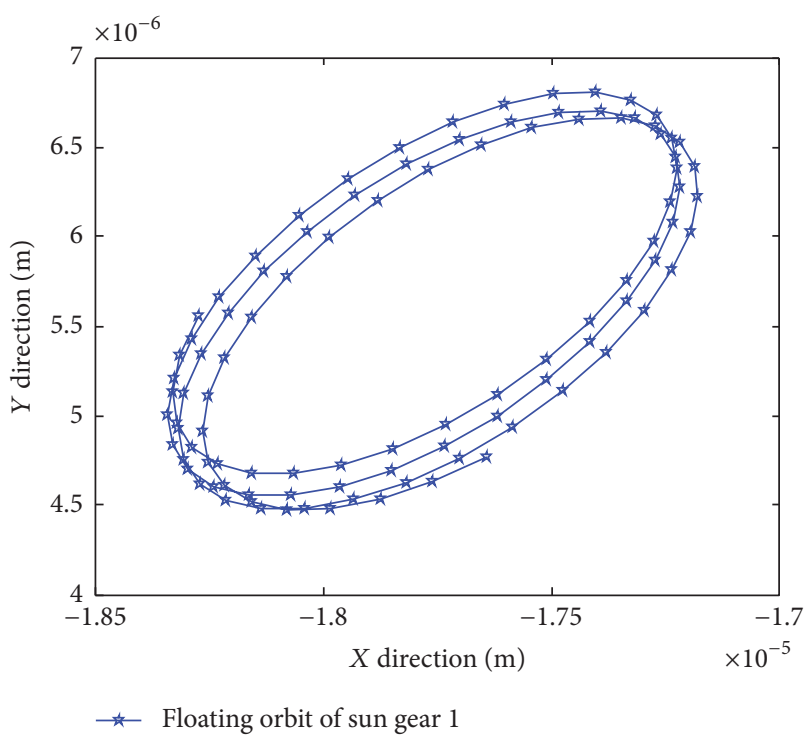

FIGURE 9: The floating orbit of first-stage sun gear $\left(S_{1}\right)$.

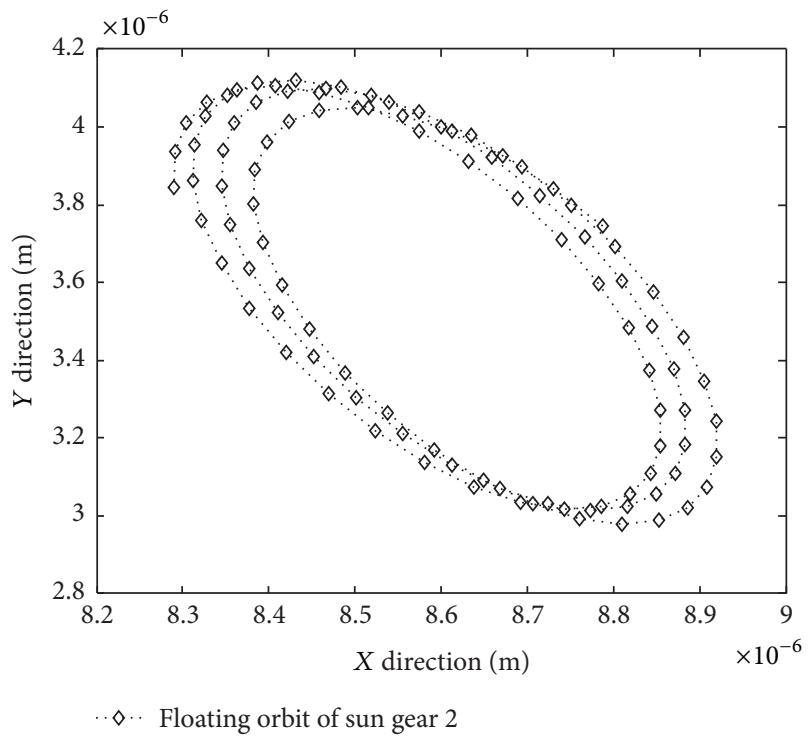

FIGURE 10: The floating orbit of second-stage sun gear $\left(S_{2}\right)$.

equal. In fact, acting force/acting torque of the third star gear is the maximum value, and acting force/acting torque of the second star gears is the minimum value.

Figure 7 is the acting torque curve from small star gear ( $p 2 i)$ of second stage to sun gear $1(s 2)$, acting torque of the first star gear in the second stage $(p 21)$ is $29.5 \mathrm{Nm}$, acting torque of the second star gear in the second stage ( $p 22)$ is $29.2 \mathrm{Nm}$, and acting torque of the third star gear in the second stage ( $p 23)$ is $30.2 \mathrm{Nm}$. The acting torque of three star gears is not the same which means the acting force of the three star gears in the second stage is not the same. The acting torque of three star gears is the same in ideal condition, which means the acting force in each star gear is equal. In fact, acting force/acting torque of the third star gear is the maximum 


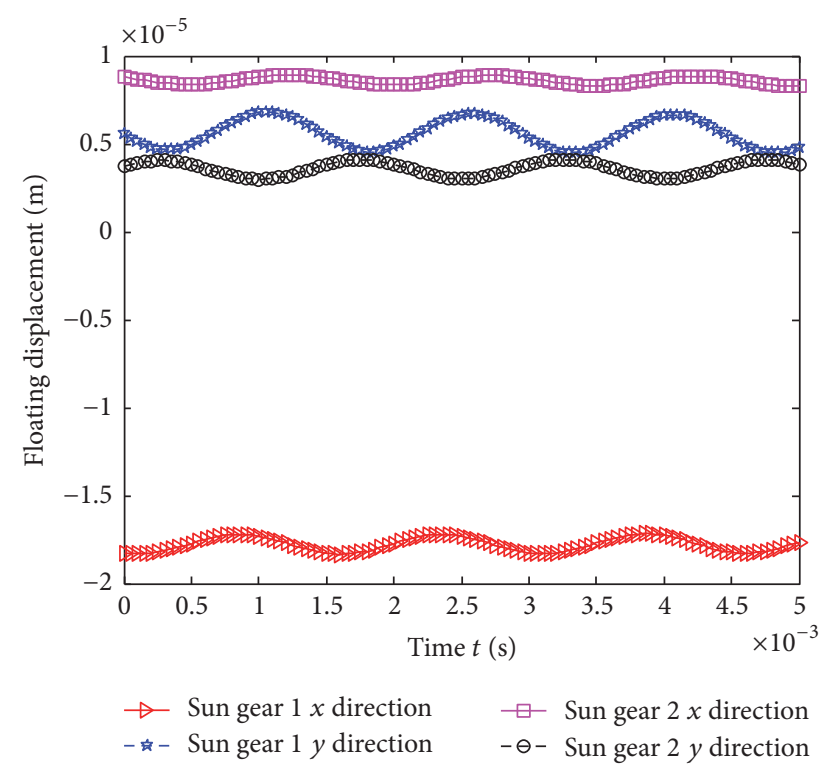

FIGURE 11: The floating amount of the sun gear.

value; the acting force/acting torque of the second star gears is the minimum value.

Figure 8 is the floating orbit of sun gear in the first stage and second stage; the floating orbit of sun gear in the first stage $(s 1)$ in Figure 8 is blue, and the floating orbit of sun gear in the second stage $(s 2)$ in Figure 8 is black. The floating orbits of sun gear in the first stage $(s 1)$ and sun gear in the second stage $(s 2)$ do not intersect and overlap. The floating orbit scope of sun gear in the first stage $(s 1)$ is from $-1.85 \times$ $10^{-5} \mathrm{~m}$ to $-1.7 \times 10^{-5} \mathrm{~m}$ in $X$ direction; the floating orbit scope of sun gear in the first stage $(s 1)$ is from $4.5 \times 10^{-6} \mathrm{~m}$ to $7.5 \times$ $10^{-6} \mathrm{~m}$ in $Y$ direction. The floating orbit scope of sun gear in the second stage $(s 2)$ is from $0.83 \times 10^{-5} \mathrm{~m}$ to $0.91 \times 10^{-5} \mathrm{~m}$ in $X$ direction; the floating orbit scope of sun gear in the second stage $(s 2)$ is from $2.6 \times 10^{-6} \mathrm{~m}$ to $4.2 \times 10^{-6} \mathrm{~m}$ in $Y$ direction.

Figures 9 and 10 are the enlarged drawing for floating orbit of first-stage sun gear $(s 1)$ and second-stage sun gear $(s 2)$, respectively. From the enlarged drawing, we can know that the floating orbit is not the single orbit, there are total of 4 orbits, and the floating orbit is not a standard circle, just like ellipse; the orbit transfers with the rotation.

Figure 11 is the floating displacements of sun gear of the first stage and second stage ( $s 1$ and $s 2)$ in each direction. Floating displacement value of sun gear 1 of the first stage $(s 1)$ in $x$ direction is $-1.8 \times 10^{-2} \mathrm{~mm}$ and floating displacement value of sun gear 1 of the first stage $(s 1)$ in $y$ direction is 0.7 $\times 10^{-3} \mathrm{~mm}$. Floating displacement value of sun gear 2 of the second stage (s2) in $x$ direction is $0.9 \times 10^{-2} \mathrm{~mm}$ and floating displacement value of sun gear 2 of the second stage (s2) in $y$ direction is $0.3 \times 10^{-3} \mathrm{~mm}$.

\section{Conclusion}

The eccentricity error, installation error, tooth thickness error, pitch section error, manufacturing error of all bearings, and floating meshing error of all gears in the two-stage star transmission system are considered in this model and the integrated angular meshing error of the two-stage external meshing line is obtained finally.

Based on the coordinated condition of angular displacement and the condition of torque balance, load sharing models of 3-road power splitting for 2-stage external meshing star gear transmission system are established. The model reflects the load sharing process caused by the load deformation of gears and the essential characteristics of the coordination of the gear corners in the power split system.

The load sharing coefficient, variation law of torque, and numerical value are obtained, which are consistent with all floating and angular displacements of gears. The floating law of the two-stage sun gear is obtained. The floating locus of input sun gear is obviously larger than that of output sun gear. And the two floating orbits do not overlap and intersect, the floating orbit is not a single trajectory, the floating amount of center gears in $x$ direction is larger, and the floating amount of sun gear 1 is larger than sun gear 2 in the corresponding direction.

\section{Conflicts of Interest}

The authors declare that they have no conflicts of interest.

\section{Acknowledgments}

This research is supported by Open Funding of the State Key Laboratory of Mechanical Transmissions (no. SKLMTKFKT-201616), National Natural Science Foundation of Tianjin (nos. 17JCQNJC04300 and 17JCQNJC03900), Fundamental Research Funds for Colleges and Universities of Tianjin (TJPUZK20170118), Tianjin Science and Technology Support Program Key Project (no. 16YFZCSY00860), and National Natural Science Foundation of China (nos. 51475330, 51365025, and U1733108). Thanks are also due to Professor Izhak Bucher of Israel Institute of Technology, Professor Matsumura Shigeki of Tokyo Institute of Technology, and Dr. Fan Qi of the Gleason Works for their constant assistance.

\section{References}

[1] A. Kahraman, "Load sharing characteristics of planetary transmissions," Mechanism and Machine Theory, vol. 29, no. 8, pp. 1151-1165, 1994.

[2] A. Kahraman, "Static load sharing characteristics of transmission planetary gear sets: Model and experiment," SAE Technical Papers, 1999.

[3] A. Bodas and A. Kahraman, "Influence of carrier and gear manufacturing errors on the static load sharing behavior of planetary gear sets," JSME International Journal Series C Mechanical Systems, Machine Elements and Manufacturing, vol. 47, no. 3, pp. 908-915, 2004.

[4] H. Ligata, A. Kahraman, and A. Singh, "An experimental study of the influence of manufacturing errors on the planetary gear stresses and planet load sharing," Journal of Mechanical Design, vol. 130, no. 4, Article ID 041701, 2008. 
[5] A. Singh, "Application of a system level model to study the planetary load sharing behavior," Journal of Mechanical Design, vol. 127, no. 3, pp. 469-476, 2005.

[6] A. Singh, "Load sharing behavior in epicyclic gears: physical explanation and generalized formulation," Mechanism and Machine Theory, vol. 45, no. 3, pp. 511-530, 2010.

[7] C. H. Wink and A. L. Serpa, "Performance assessment of solution methods for load distribution problem of gear teeth," Mechanism and Machine Theory, vol. 43, no. 1, pp. 80-94, 2008.

[8] H. Bao and R. Zhu, "Impacts of eccentric and installation errors on static load sharing behaviors of encased differential herringbone trains," Journal of South China University of Technology (Science and Technology), vol. 37, no. 3, pp. 553-557, 2006.

[9] Z. Zhu and R. Zhu, "Floating displacement static analysis of basic floating part of 2-stage star gear trains," Journal of Central South University (Science and Technology), vol. 39, no. 8, pp. 1925, 2011

[10] J.-F. Du, Z.-D. Fang, B.-B. Wang, and H. Dong, "Study on load sharing behavior of planetary gear train based on deformation compatibility," Journal of Aerospace Power, vol. 27, no. 5, pp. 1166-1171, 2012 (Chinese).

[11] H. Dong, Z.-D. Fang, B.-B. Wang, and J.-F. Du, "Load sharing characteristics analysis of power split system based on deflection compatibility and clearance floating," Hangkong Dongli Xuebao/Journal of Aerospace Power, vol. 28, no. 4, pp. 872-877, 2013.

[12] S. Mo, Y. Zhang, Q. Wu, H. Houjoh, and S. Matsumura, "Research on natural characteristics of double-helical star gearing system for GTF aero-engine," Mechanism and Machine Theory, vol. 106, pp. 166-189, 2016.

[13] S. Mo, Y. Zhang, Q. Wu, S. Matsumura, and H. Houjoh, "Load sharing behavior analysis method of wind turbine gearbox in consideration of multiple-errors," Journal of Renewable Energy, vol. 97, pp. 481-491, 2016.

[14] S. Mo, Y. Zhang, Q. Wu et al., "Load sharing behavior of star gearing reducer for geared turbofan engine," Chinese Journal of Mechanical Engineering, vol. 30, no. 4, pp. 796-803, 2017.

[15] S. Mo, Y. Zhang, and Q. Wu, "Research on multiple-split load sharing of two-stage star gearing system in consideration of displacement compatibility," Mechanism and Machine Theory, vol. 88, pp. 1-15, 2015.

[16] G. Mantriota, "Power split transmissions for wind energy systems," Mechanism and Machine Theory, vol. 117, no. 11, pp. 160-174, 2017.

[17] Z.-B. Zhu, R.-P. Zhu, and H.-Y. Bao, "Non-linear dynamic study of 2-stage star gear train," Hangkong Dongli Xuebao/Journal of Aerospace Power, vol. 22, no. 11, pp. 1963-1970, 2007.

[18] J.-G. Gu, Z.-D. Fang, H. Pang, and C. Wang, "Modeling and load analysis of spiral bevel gears power split system," Journal of Aerospace Power, vol. 24, no. 11, pp. 2625-2630, 2009 (Chinese).

[19] J. Shigley and C. Mischke, Mechanical Engineering Design, McGraw-Hill, Boston, Mass, USA, 6th edition, 2001. 


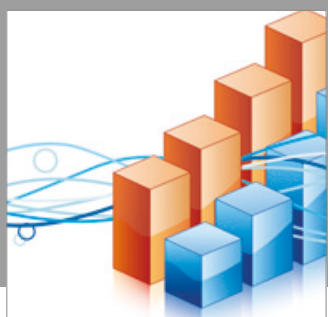

Advances in

Operations Research

vatersals

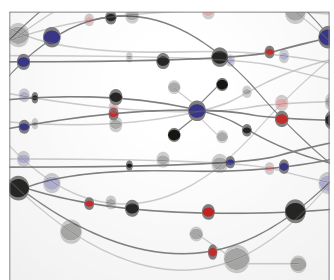

\section{The Scientific} World Journal
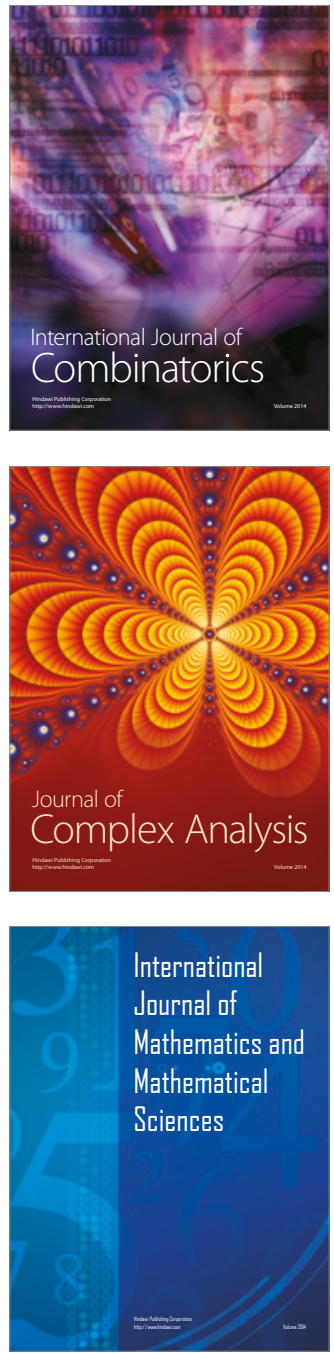
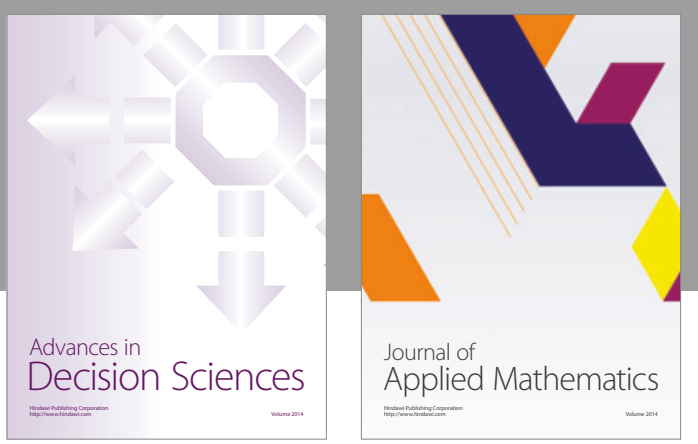

Algebra

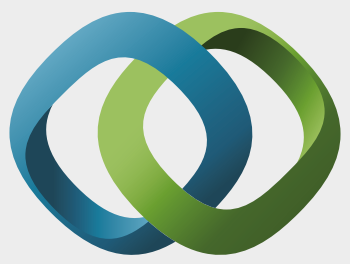

\section{Hindawi}

Submit your manuscripts at

https://www.hindawi.com
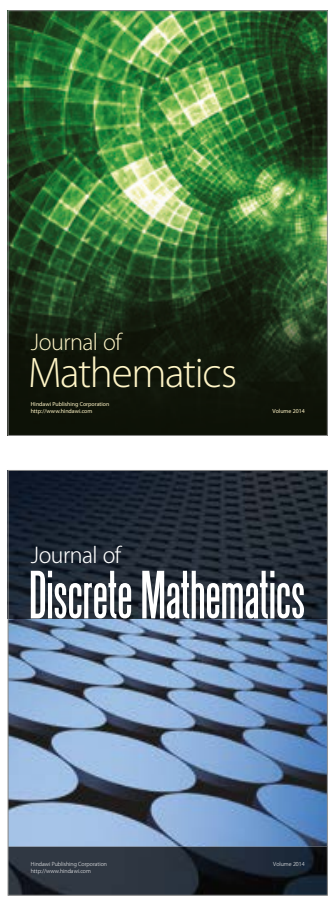

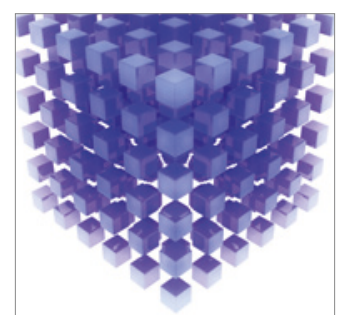

Mathematical Problems in Engineering
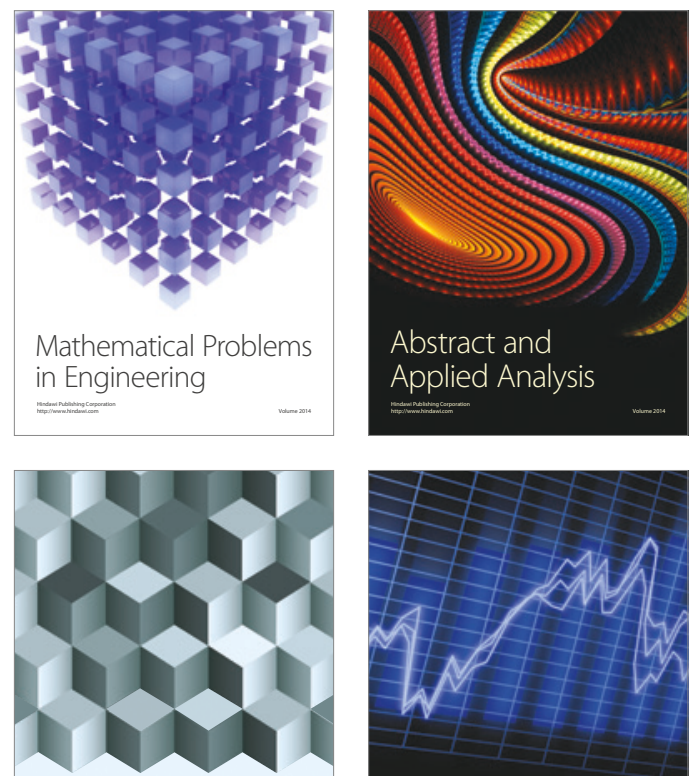

Journal of

Function Spaces

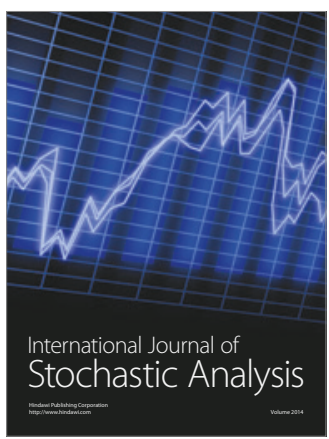

Probability and Statistics
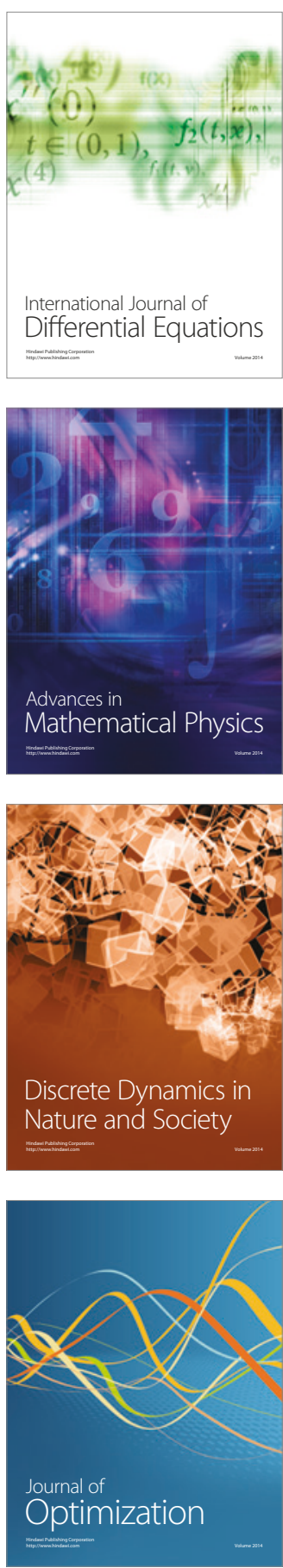